Abstract 58 Table 1 Baseline demographic

\begin{tabular}{|l|c|c|c|}
\hline & $\begin{array}{c}\text { Any femoral access } \\
\text { (n= 41) }\end{array}$ & $\begin{array}{c}\text { Bi-radial access } \\
\text { (n=109) }\end{array}$ & p-value \\
\hline Age at operation (years) & $68(64,72)$ & $64(56,70)$ & 0.02 \\
\hline Female & $14(34.2)$ & $17(15.6)$ & 0.01 \\
\hline BMI & $28.9(27.3,33.3)$ & $29.9(26.9,34.4)$ & 0.53 \\
\hline Hx of Hypertension & $37(90.2)$ & $87(79.8)$ & 0.13 \\
\hline Hx of Diabetes & $15(36.6)$ & $24(22.0)$ & 0.07 \\
\hline Hx of Previous CABG & $61(52,69)$ & $73(62,85)$ & 0.002 \\
\hline Left ventricular function & $15(36.6)$ & $20(18.4)$ & 0.02 \\
\hline Normal & & & \\
\hline Mild & $23(56.1)$ & $83(76.2)$ & 0.016 \\
\hline Moderate & $14(34.2)$ & $14(12.8)$ & 0.003 \\
\hline Severe & $3(7.3)$ & $6(5.5)$ & 0.71 \\
\hline
\end{tabular}

Abstract 58 Table 2 Lesion characteristic and outcome

\begin{tabular}{|l|c|c|c|}
\hline & $\begin{array}{c}\text { Any femoral access } \\
(\mathbf{n = 4 1 )}\end{array}$ & $\begin{array}{c}\text { Bi-radial access } \\
\text { (n=109) }\end{array}$ & p-value \\
\hline Previous CTO failure & $15(36.6)$ & $25(22.9)$ & 0.09 \\
\hline J-CTO score & $3.3 \pm 0.9$ & $3.0 \pm 0.8$ & 0.04 \\
\hline Presence of collateral vessels & $38(92.7)$ & $98(89.9)$ & 0.76 \\
\hline In-stent CTO & $4(9.8)$ & $2(1.8)$ & $<0.05$ \\
\hline Procedural failure & $9(22.0)$ & $14(12.8)$ & 0.17 \\
\hline Where J-CTO score >3 & $4 / 21(19.1)$ & $7 / 32(21.9)$ & $>0.99$ \\
\hline Procedure Length (mins) & $131.9 \pm 46.9$ & $109.4 \pm 44.8$ & 0.016 \\
\hline Radiation Dose (CGYcm2) & $24314 \pm 15357$ & $18694 \pm 10381$ & 0.052 \\
\hline Contrast Dose (mi) & $315.7 \pm 122.4$ & $277.9 \pm 133.0$ & 0.041 \\
\hline Any complication & $8(19.5)$ & $11(10.1)$ & 0.12 \\
\hline Length of stay (days) & $0.6 \pm 1.1$ & $0.4 \pm 1.3$ & 0.021 \\
\hline
\end{tabular}

\section{THE EFFECT OF A VIRTUAL REALITY IMMERSIVE EXPERIENCE UPON ANXIETY LEVELS IN PATIENTS UNDERGOING CARDIAC CATHETERISATION: THE VIRTUAL CATH TRIAL}

${ }^{1}$ Holly Morgan*, ${ }^{2}$ Sean Michael Gallagher. ${ }^{1} D r_{;}{ }^{2}$ University Hospital of UK

\subsection{6/heartjnl-2019-BCS.57}

Introduction Patients undergoing cardiac catheterisation are understandably anxious. This is due to a lack of familiarity with both the hospital environment and the planned procedure. Anxiety may negatively affect their patient experience. Appropriate patient information can help improve understanding and reduce anxiety. In particular, video-based patient information prior to cardiac catheterisation has been shown to improve patient's knowledge and reduce peri-procedural anxiety. Generic video-based patient information about the cardiac catheterisation procedure is widely available. Ideally any patient information delivered pre-cardiac catheterization would be specific to the hospital delivering care. The use of virtual reality (VR) in healthcare is novel, but expanding rapidly. The immersive nature of VR allows patients a unique opportunity to prepare for the procedure and environment within which they will be treated. To date, the use of VR to prepare patients for invasive cardiac procedures has not been studied.

Aim The aim of this study is to assess whether the use of an immersive VR experience decreases peri-procedural anxiety in patients undergoing cardiac catheterisation. We will also assess whether the VR experience improves overall patient satisfaction.

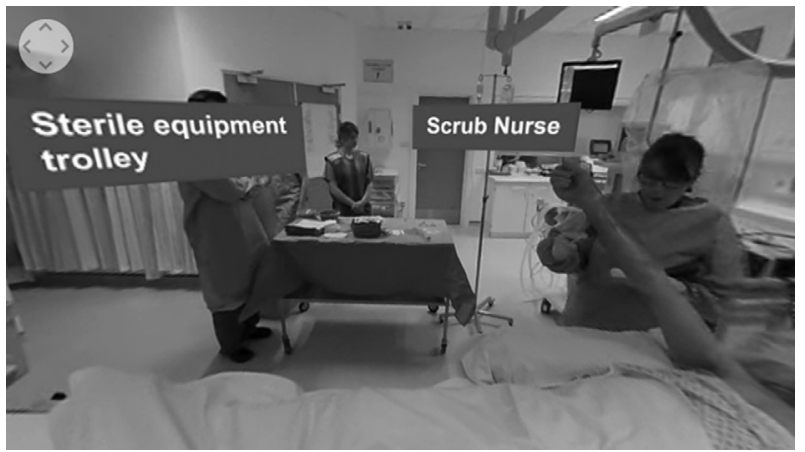

Abstract 59 Figure 1

Methods With the help of a local media company, a VR cardiac catheterisation video was produced (figure 1 depicts a screenshot from the VR video). The video is watched with a VR headset to create a 360 immersive experience. We are undertaking a single-centre randomised control trial comparing the use of an immersive VR experience 1 week prior to catheterisation with standard pre-procedural care. Pre procedural anxiety levels and procedural knowledge are assessed by questionnaire, using the validated six-item short-form of the Strait Trait Anxiety Inventory (STAI). A satisfaction questionnaire is also completed before the patient is discharged.

Results Data collection is currently underway and is due to finish in April 2019. Preliminary review of pilot results shows trend towards reduced anxiety in VR cohort $(n=45 ; 21 C$, 24VR; anxiety scores $21.5 \mathrm{v} 17.6$ ) Informal feedback suggests patients enjoy the VR experience and find it a helpful adjunct 
to the usual pre-procedure care. Full data analysis will be completed by May 2019.

Conclusion We aim to assess whether the use of an immersive VR experience improves patient familiarity with cardiac catheterisation, thereby reducing peri-procedural anxiety. If confirmed, we plan to make the immersive VR experience available to all patients undergoing angiography in our centre. Further work includes expanding the VR resource to cover other cardiac procedures.

Conflict of Interest None

\section{AN ATLAS OF COMPUTED FFR IN COMMON PATTERNS OF CORONARY ARTERY DISEASE}

${ }^{1}$ Roberto Newcombe*, ${ }^{1}$ Rebecca Gosling, 'Julian Gunn, ${ }^{1}$ Andrew Narracott, 'Rodney Hose, ${ }^{2}$ Paul Morris, ${ }^{1}$ Patricia Lawford. 'University of Sheffield; ' ${ }^{2}$ Department of Infection, Immunity and Cardiovascular Disease, Univeristy of Sheffield

\subsection{6/heartjnl-2019-BCS.58}

Introduction Fractional flow reserve (FFR) is the gold standard method for assessing the physiological significance of coronary artery lesions. A 'virtual' FFR can be computed from angiographic images, using computational fluid dynamics, avoiding the need for a pressure wire. FFR is influenced by several factors including; stenosis severity, length of stenosis, vessel size and myocardial resistance. However, how each of these contribute to the overall FFR is not fully understood. We sought to create a range of $3 \mathrm{D}$ geometries, with varying characteristics and determine their corresponding vFFRs, to inform clinicians about the impact upon blood flow caused by commonly encountered disease patterns.

Methods Geometries were created using ANSYS Design Modeler $^{\mathrm{TM}}$ that included stenoses of different shape, severity, number and length, within straight and branched models using variations on a basic standard vessel size (a rigid tubular $3.5 \mathrm{~mm}$ diameter main vessel, $50 \mathrm{~mm}$ long, with any branches obeying Huo-Kassab's law). vFFR values were calculated using our in-house VIRTUheart ${ }^{\mathrm{TM}}$ workflow. Results were displayed in easy-to-understand pictorial form.

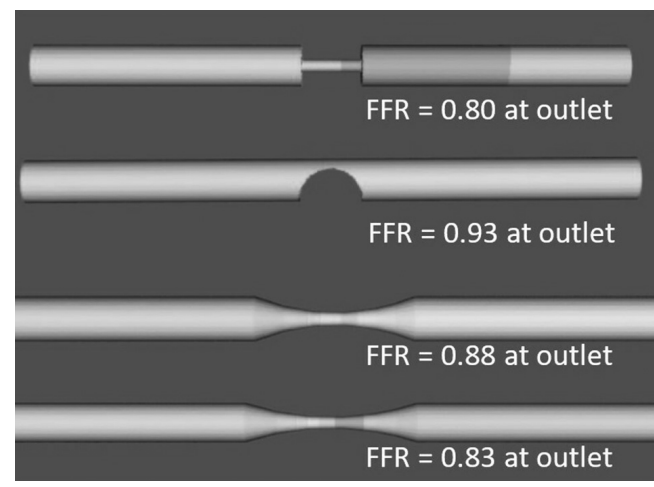

Abstract 60 Figure 1 Geometries 1-4 with vFFR values. Produced by the VIRTUheart workflow ${ }^{\mathrm{TM}}$ in the Department of Infection, Immunity and Cardiovascular Disease, at the University of Sheffield. (Newcombe et al., 2019).

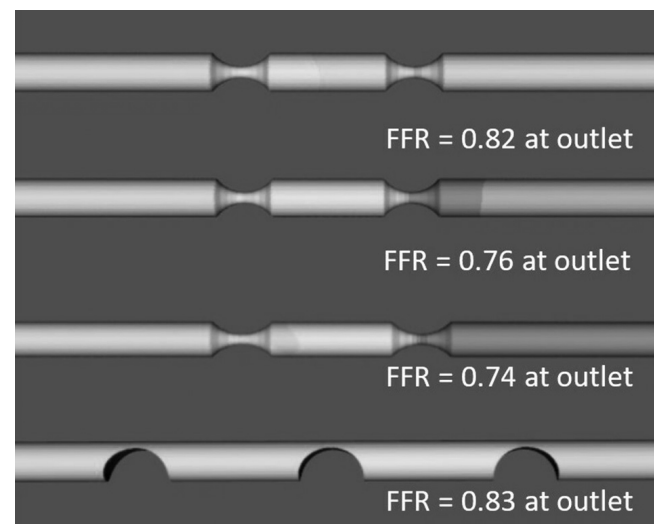

Abstract 60 Figure 2 Geometries 5-8 with vFFR values. Produced by the VIRTUheart workflow ${ }^{\mathrm{TM}}$ in the Department of Infection, Immunity and Cardiovascular Disease, at the University of Sheffield. (Newcombe et al., 2019).

Abstract 60 Table 1 Example of some key FFR results obtained from our straight vessel geometries

\begin{tabular}{|c|c|c|c|c|c|}
\hline Lesion & $\begin{array}{l}\text { Diamete } \\
\mathrm{X} \text { and } \mathrm{Y}\end{array}$ & $\begin{array}{l}\text { eduction in } \\
\text { rection }(\%)\end{array}$ & $\begin{array}{c}\text { Rounded/ } \\
\text { Rectangular } \\
\text { lesion }\end{array}$ & $\begin{array}{c}\text { Number of } \\
\text { lesions } \\
\text { (separated } \\
\text { by } 10 \mathrm{~mm} \text { ) }\end{array}$ & $\begin{array}{c}\text { FFR } \\
\text { (at outlet) }\end{array}$ \\
\hline $5 \mathrm{~mm}$ concentric & $X=70$ & $Y=70$ & Rectangular & 1 & 0.80 \\
\hline $5 \mathrm{~mm}$ eccentric & $X=0$ & $Y=80$ & Rounded & 1 & 0.93 \\
\hline $15 \mathrm{~mm}$ concentric & $X=70$ & $Y=70$ & Rounded & 1 & 0.88 \\
\hline $15 \mathrm{~mm}$ concentric $*$ & $X=70$ & $\mathrm{Y}=70$ & Rounded & 1 & 0.83 \\
\hline $5 \mathrm{~mm}$ concentric & $X=70$ & $Y=70$ & Rounded & 2 & 0.82 \\
\hline $5 \mathrm{~mm}$ concentric* & $X=70$ & $Y=70$ & Rounded & 2 & 0.76 \\
\hline $5 \mathrm{~mm}$ concentric ${ }^{\dagger}$ & $X=70$ & $Y=70$ & Rounded & 2 & 0.74 \\
\hline $5 \mathrm{~mm}$ eccentric & $X=0$ & $Y=80$ & Rounded & 3 & 0.83 \\
\hline
\end{tabular}

* = Indicates Microvascular Resistance was set to 6.721E9, 2E9 lower than the standard 8.721E9 value used.

$\dagger=$ Indicates vessel Diameter was set to $3.0 \mathrm{~mm}$ rather than standard $3.5 \mathrm{~mm}$ diameter used. 